AGrária

Revista Brasileira de Ciências Agrárias

ISSN (on line): 1981.0997

v.7, n.1, p.104-110, jan.-mar., 2012

Recife, PE, UFRPE. www.agraria.ufrpe.br

DOI:10.5039/agraria.v7i1a1648

Protocolo 1648 - 21/06/2011 *Aprovado em 09/09/2011

Rilner A. Flores ${ }^{1,2}$

Thiago B. F. de Almeida ${ }^{1}$

Lucas S. Politi ${ }^{1,3}$

Renato de M. Prado 1,4

José C. Barbosa ${ }^{1,4}$

${ }^{1}$ Universidade Estadual Paulista Júlio de Mesquita Filho, Faculdade de Ciências Agrárias e Veterinárias de Jaboticabal, Via de Acesso Professor Paulo Donato Castellane, s/n, CEP 14884-900 - Jaboticabal-SP Brasil. Fone: (016) 3209-2672. Fax: (016) 3202-4275. E-mail: rilner1@hotmail.com; thibalmeida@gmail.com; lucasspoliti@yahoo.com.br; rmprado@fcav.unesp.br; jcbarbosa@fcav.unesp.br

2 Bolsista de Doutorado do CNPq

${ }^{3}$ Bolsista de Mestrado da CAPES

${ }^{4}$ Bolsista de Produtividade em Pesquisa do CNPq

\section{Crescimento e desordem nutricional em pimenteira malagueta cultivada em soluções nutritivas suprimidas de macronutrientes}

RESUMO

Apesar da importância da pimenta no mundo, são escassas informações sobre diagnose foliar da cultura. Diante disto, objetivou-se avaliar o efeito da omissão de macronutrientes no crescimento e no estado nutricional da pimenteira, variedade malagueta, cultivada em solução nutritiva. Os tratamentos foram constituídos por: solução nutritiva completa e com omissão individual de $\mathrm{N}, \mathrm{P}, \mathrm{K}, \mathrm{Ca}, \mathrm{Mg}$ e S, sob delineamento inteiramente casualizado, com três repetições. As plantas foram cultivadas em solução nutritiva de Hoagland \& Arnon, em vasos com $8 \mathrm{~L}$ de volume. Aos 56 dias após o transplantio, foram avaliadas a altura das plantas, 0 diâmetro do colmo, o número de folhas, a área foliar, o índice relativo de clorofila, a massa da matéria seca da planta, os teores dos macronutrientes na parte aérea e na raiz e realizada a descrição das desordens nutricionais. As omissões dos macronutrientes interferiram nas concentrações dos nutrientes nas diversas partes da planta, 0 que limitou o crescimento vegetativo e diminuiu a produção de matéria seca, ocasionando os sintomas característicos de deficiência de cada nutriente. Os nutrientes que mais limitaram o crescimento da pimenteira foram nitrogênio, cálcio e potássio, entretanto, o cálcio foi o elemento mais exigido pela planta.

Palavras-chave: Capsicum frutescens, deficiência nutricional, nutrição mineral.

\section{Growth and nutritional disorder in chili pepper grown in nutrient solutions with macronutrient omission}

\begin{abstract}
Despite the importance of pepper in the world, there is little information about the culture's foliar diagnosis. By this fact, the macronutrient omission effect on chili pepper growth and nutritional status, grown under nutrient solution were evaluated. The treatments were: full nutrient solution and nutrient solution without $\mathrm{N}, \mathrm{P}, \mathrm{K}, \mathrm{Ca}, \mathrm{Mg}$, and S, under a completely randomized design with three replications. Plants were grown in a Hoagland \& Arnon nutrient solution, in $8 \mathrm{~L}$ pots. 56 days after transplant, the plant height, stem diameter, leaf number, leaf area, the relative chlorophyll content, the plant dry matter, the macronutrient contents of the shoots and roots were evaluated, and made of description of nutritional disorders. The macronutrients omission interfered in the nutrients concentrations in different parts of the plant, which limited the vegetative growth and decreased the dry matter production, causing the characteristic deficiency symptoms for each nutrient. The nutrients that most limited the pepper growth were nitrogen, calcium, and potassium, however, calcium was the most required element by the plant.
\end{abstract}

Key words: Capsicum frutescens, nutritional deficiency, mineral nutrition. 


\section{INTRODUÇÃO}

A importância da cultura da pimenta ocorre devido à rentabilidade, que agrega alto valor ao produto, e ao aspecto social, por empregar elevada mão-de-obra (Rufino \& Penteado, 2006). Esta cultura, originária de clima tropical, é sensível a baixas temperaturas, e por isso deve ser cultivada, preferencialmente, nos meses com temperaturas quentes, variando de 21 a $30^{\circ} \mathrm{C}$ (Chaves, 2008).

No Brasil a produção da pimenta foi de 18700 t na safra de 2006, destacando-se a região Nordeste, a maior produtora, com produção de $6400 \mathrm{t}$ (34,2\%), seguida pela região Sudeste com 5600 t (29,9\%), e pela região Norte com 4200 t (22,5\%) (IBGE, 2006). Entretanto, o mercado para pimentas no Brasil é considerado secundário em relação às outras hortaliças. Porém, este cenário está modificando-se rapidamente pela exploração de novos tipos de pimentas e o desenvolvimento de novos produtos, com valor agregado (conservas ornamentais, geleias especiais e outras formas processadas), tendo um mercado promissor (Chaves, 2008).

O emprego da hidroponia permite o uso de soluções nutritivas balanceadas, na ausência ou na presença de substratos naturais ou artificiais, constituindo-se de um sistema de produção intensivo (Rodrigues, 2002). Um dos poucos trabalhos de pesquisa desenvolvido no Brasil, que abordam estudos sobre a nutrição mineral em pimenteiras (conteúdo de nutrientes), foi realizado em cultivo com substrato de sílica (Veloso \& Muraoka, 1993). Esse fato é preocupante, pois é conhecida a importância dos nutrientes, tendo funções essenciais e específicas, e a sua deficiência poderá causar prejuízos no metabolismo das plantas e induzir os sintomas visuais de carência, característicos para cada nutriente e que dependem também da intensidade, da cultivar e de fatores ambientais.

A desordem nutricional, seja por deficiências, excessos, e/ ou desequilíbrios, causam diminuição na produção das culturas. Essa diminuição na colheita é, em geral, precedida por sintomas visuais que, geralmente, são mais evidentes nas folhas, embora a produção já possa estar comprometida mesmo antes da manifestação destes sintomas (Malavolta et al., 1997). A diagnose visual de deficiências nutricionais, concomitantemente com o conhecimento dos teores dos nutrientes, pode constituir uma ferramenta auxiliar para a avaliação do estado nutricional e com implicações na recomendação de adubação adequada para qualquer cultura (Epstein, 1975).

Diante disso, objetivou-se avaliar o efeito da omissão de macronutrientes no crescimento e no estado nutricional da pimenteira, variedade malagueta, cultivada em solução nutritiva.

\section{MATERIAL e MÉTOdos}

Foi realizado um experimento em casa de vegetação na Faculdade de Ciências Agrárias e Veterinárias da Unesp, campus de Jaboticabal, estado de São Paulo, utilizando-se a pimenta (Capsicum frutescens), variedade malagueta, cultivada em vasos contendo 8L de solução nutritiva.
Foram avaliados sete tratamentos: 1- solução nutritiva completa (N, P, K, Ca, Mg, S, B, Cl, Cu, Fe, Mn, Mo e Zn); 2omissão de nitrogênio (-N); 3- omissão de fósforo (-P); 4omissão de potássio (-K); 5- omissão de cálcio (-Ca); 6omissão de magnésio (-Mg); 7- omissão de enxofre (-S), dispostos em um delineamento inteiramente casualizado, com três repetições. Realizou-se durante o desenvolvimento do experimento o rodízio dos vasos a cada semana, para proporcionar as mesmas condições de temperatura, umidade e luminosidade para os tratamentos.

Para a condução do experimento, foram utilizadas mudas de pimenteira com 20 dias de idade, sendo transplantada uma planta para cada vaso, contendo inicialmente solução nutritiva de Hoagland \& Arnon (1950) diluída a 50\%, da concentração usual, na primeira semana, e a $100 \%$ a partir da segunda semana de cultivo até o final do experimento.

As soluções nutritivas foram preparadas com água deionizada e substituídas a cada 15 dias. $\mathrm{O}$ pH foi ajustado a 5,5 $\pm 0,5$ com solução de $\mathrm{NaOH}$ ou $\mathrm{HCl}$ 0,1M. Para a reposição da água evapotranspirada utilizou-se água deionizada, sendo a solução nutritiva oxigenada constantemente, com o auxílio do compressor de ar.

As plantas foram colhidas 56 dias após o transplantio (DAT). Nessa ocasião, determinou-se a altura das plantas, desde o colo da planta até o ápice da última folha desenvolvida, o diâmetro do caule, o número total de folhas por planta, a medida indireta do teor de clorofila a partir da leitura do índice relativo de clorofila (ICR), em dez folhas por unidade experimental com auxílio do aparelho da OPTI-Sciences ${ }^{\circledR}$ modelo CCM-200, e a área foliar, com o aparelho LI-3100 Area Meter.

O material vegetal colhido foi lavado com água deionizada e separado em parte aérea e raízes, colocado para secar em estufa de ventilação forçada a $65^{\circ} \mathrm{C}$ até massa constante, determinando-se a massa da matéria seca e os teores dos macronutrientes, conforme método descrito por Bataglia et al. (1983). Estas duas variáveis foram utilizadas para calcular o conteúdo dos nutrientes.

Durante o período experimental, realizaram-se, diariamente, a partir da primeira semana de cultivo com $100 \%$ da solução nutritiva, as descrições da sintomatologia visual de deficiência nutricional nas plantas para cada tratamento.

Os dados obtidos foram submetidos à análise de variância e ao teste de Dunnett $(\mathrm{p}<0,05)$, utilizando-se o software SAS versão 9.0. Optou-se em indicar a diferença significativa apontada pelo teste de comparação de médias, em relação aos tratamentos com as omissões dos nutrientes e o tratamento com solução nutritiva completa.

\section{RESULTADOS E Discussão}

\section{Nitrogênio}

A omissão de $\mathrm{N}$ diminuiu a altura das plantas, o diâmetro do colmo, a área foliar, o número de folhas e o índice relativo de clorofila (Tabela 1). Com isso, a produção de matéria seca na parte aérea, nas raízes e na planta inteira foi reduzida em relação ao tratamento com a solução completa (Tabela 2). 
Tabela 1. Variáveis vegetativas e índice relativo da clorofila (IRC) das plantas de pimenta, em função da omissão de macronutrientes na solução nutritiva. Jaboticabal, 2010

Table1 Vegetative variables and relative chlorophyll content (ICR) of pepper plants, as a function of the macronutrients omission in the nutrient solution. Jaboticabal, São Paulo, Brazil, 2010

\begin{tabular}{|c|c|c|c|c|c|}
\hline \multirow[t]{2}{*}{ Tratamentos } & \multirow{2}{*}{$\begin{array}{l}\text { Altura } \\
\mathrm{cm}\end{array}$} & \multirow[t]{2}{*}{ Diâmetro do colmo } & \multirow[t]{2}{*}{ Área foliar } & \multirow[t]{2}{*}{ Número de folhas } & \multirow[t]{2}{*}{ ICR } \\
\hline & & & & & \\
\hline Solução completa & 29,2 & 6,1 & 427,7 & 32 & 26,9 \\
\hline$-N$ & 16,2 & 3,9 & $67,2^{-}$ & 15 & $4,6^{-}$ \\
\hline - $P$ & 22,3 & $4,7^{-}$ & 203,5 & $19^{-}$ & $11,4^{-}$ \\
\hline$-\mathrm{K}$ & 14,8 & $3,6^{-}$ & $82,4^{-}$ & $16^{-}$ & $9,0^{-}$ \\
\hline - $\mathrm{Ca}$ & $14,6^{-}$ & $3,6^{-}$ & $65,0^{\circ}$ & $16^{-}$ & $21,4^{-}$ \\
\hline$-\mathrm{Mg}$ & $23,7^{-}$ & 5,3 & $307,4^{-}$ & $27^{-}$ & $7,1^{-}$ \\
\hline$-S$ & $23,7^{-}$ & 5,2 & 350,9 & 28 & $14,8^{-}$ \\
\hline DMS & 5,4 & 1,3 & 74,9 & 3,4 & 1,9 \\
\hline CV (\%) & 11,1 & 11,6 & 14,6 & 6,6 & 5,8 \\
\hline
\end{tabular}

${ }_{+}$e - Significativo e superior à testemunha e significativo e inferior à testemunha, na coluna, pelo teste Dunnett a 5\% de probabilidade

Esses resultados são semelhantes aos obtidos por Veloso \& Muraoka (1993), que verificaram menor crescimento da pimenta-do-reino, em relação ao tratamento completo, aos 30 dias após o início dos sintomas visuais.

Essa redução nas variáveis de crescimento vegetativo em função da omissão de nitrogênio é amplamente discutida na literatura devido à importância do nutriente para a nutrição das plantas. Segundo Filgueira (2003), o nitrogênio favorece o crescimento vegetativo, o acúmulo de massa, o aumento da área foliar e, consequentemente, a expressão do potencial

Tabela 2. Produção de matéria seca das plantas de pimenta, em função da omissão de macronutrientes na solução nutritiva. Jaboticabal, 2010

Table 2. Dry matter production of pepper plants, as a function of the macronutrients omission in the nutrient solution. Jaboticabal, São Paulo, Brazil, 2010

\begin{tabular}{lccc}
\hline Tratamento & \multicolumn{3}{c}{ Matéria seca } \\
\cline { 2 - 4 } & Parte aérea & Raiz & Planta inteira \\
& g planta-1 & & \\
\hline Solução completa & 4,8 & 1,3 & 6,2 \\
- N & $0,9^{-}$ & $0,6^{-}$ & $1,5^{-}$ \\
- P & $2,5^{-}$ & $1,0^{-}$ & $3,6^{-}$ \\
- K & $1,4^{-}$ & $0,2^{-}$ & $1,6^{-}$ \\
- Ca & $1,4^{-}$ & $0,2^{-}$ & $1,6^{-}$ \\
- Mg & $3,4^{-}$ & $1,0^{-}$ & 4,5 \\
- S & 3,5 & 0,8 & 4,3 \\
DMS & 1,1 & 0,3 & 1,3 \\
CV (\%) & 17,9 & 16,2 & 16,8 \\
\hline
\end{tabular}

e - Significativo e superior à testemunha e significativo e inferior à testemunha, na coluna, pelo teste Dunnett a $5 \%$ de probabilidade
Tabela 3. Teores de nutrientes na parte aérea e raízes das plantas de pimenta, em função da omissão de macronutrientes na solução nutritiva. Jaboticabal, 2010

Table 3. Nutrient contents in the shoot and roots of pepper plants, as a function of the macronutrients omission in the nutrient solution. Jaboticabal, São Paulo, Brazil, 2010

\begin{tabular}{|c|c|c|c|c|c|c|}
\hline Tratamento & $\mathrm{N}$ & $P$ & $\mathrm{~K}$ & $\mathrm{Ca}$ & $\mathrm{Mg}$ & $\mathrm{S}$ \\
\hline
\end{tabular}

Parte aérea

$\begin{array}{lcccccc}\text { Solução completa } & 44,8^{-} & 4,4 & 9,8^{-} & 89,7 & 18,5 & 12,7 \\ \text { - N } & 18,6^{-} & 7,7^{+} & 6,2^{-} & 79,7 & 25,9 & 13,0 \\ \text { - P } & 42,9 & 0,8^{-} & 9,0 & 63,0^{-} & 19,7 & 9,3 \\ \text { - K } & 38,3^{-} & 4,1 & 4,4^{-} & 26,3^{-} & 16,9 & 2,0^{-} \\ \text {- Ca } & 32,9^{-} & 3,4 & 8,5 & 57,7^{-} & 6,5^{-} & 4,0^{-} \\ \text {- Mg } & 34,2^{-} & 4,9 & 11,6 & 52,7^{-} & 21,4 & 11,7 \\ \text { - S } & 34,4^{-} & 4,4 & 7,4^{-} & 86,0 & 5,1^{-} & 1,3^{-} \\ \text {DMS } & 3,7 & 1,0 & 1,7 & 16,5 & 9,1 & 4,1 \\ \text { CV (\%) } & 4,4 & 9,8 & 9,1 & 10,7 & 23,6 & 22,6\end{array}$

\begin{tabular}{lcccccc} 
Solução completa & $31,4^{-}$ & 5,3 & 11,5 & 84,7 & 9,6 & 2,0 \\
- N & $17,0^{-}$ & $6,6^{+}$ & $8,9^{-}$ & 81,3 & 9,5 & 2,3 \\
- P & $32,9^{+}$ & $1,1^{-}$ & $9,2^{-}$ & $77,0^{-}$ & 9,6 & 2,0 \\
- K & $49,0^{+}$ & - & - & $6,0^{-}$ & 9,0 & 1,3 \\
- Ca & $42,5^{+}$ & $3,2^{-}$ & $6,6^{-}$ & $15,3^{-}$ & $1,8^{-}$ & 2,7 \\
- Mg & $39,1^{+}$ & 4,5 & 12,5 & $63,7^{-}$ & 10,4 & 3,0 \\
- S & 33,5 & 4,7 & $5,5^{-}$ & 78,3 & $20,7^{+}$ & $12,3^{+}$ \\
DMS & 4,7 & 0,8 & 1,4 & 13,2 & 2,8 & 3,2 \\
CV (\%) & 5,6 & 9,1 & $7,0^{-}$ & 9,6 & 11,6 & 36,2 \\
\hline
\end{tabular}

${ }^{+} \mathrm{e}^{-}-$Significativo e superior à testemunha e significativo e inferior à testemunha, na coluna, pelo teste Dunnett a $5 \%$ de probabilidade 
produtivo da cultura. Isso ocorre em função dos efeitos deste nutriente nos processos bioquímicos e fisiológicos da planta, como na absorção iônica, fotossíntese, respiração, multiplicação e diferenciação celular (Malavolta et al., 1997).

O tratamento com solução nutritiva completa apresentou teor de $\mathrm{N}$ na parte aérea de 44,8 $\mathrm{g} \mathrm{kg}^{-1}$, enquanto no tratamento com omissão deste nutriente obteve-se teor de $18,6 \mathrm{~g} \mathrm{~kg}^{-1}$ (Tabela 3).

Com a omissão de nitrogênio, a planta da pimenta encontrava-se deficiente, quando comparada aos teores foliares considerados adequados por Trani et al. (1997) (30 a $45 \mathrm{~g} \mathrm{~kg}^{-1}$ ). A omissão de $\mathrm{N}$ na solução nutritiva aumentou os teores foliares de $\mathrm{P}, \mathrm{Mg}$ e $\mathrm{S}$, e diminuiu os de $\mathrm{K}$ e Ca, em comparação com a solução nutritiva completa (Tabela 3). Quando avaliados os teores de $\mathrm{N}$ nas raízes, a solução nutritiva completa apresentou teor de $\mathrm{N}$ de $31,4 \mathrm{~g} \mathrm{~kg}^{-1}$, enquanto a omissão de $\mathrm{N}$ diminuiu o teor deste nutriente nas raízes para $17,0 \mathrm{~g} \mathrm{~kg}^{-1}$. A omissão de $\mathrm{N}$ diminuiu também os teores radiculares de $\mathrm{K}$, Ca e $\mathrm{Mg}$, e aumentou $\mathrm{P}$ e $\mathrm{S}$, em comparação com a solução nutritiva completa (Tabela 3).

A omissão de nitrogênio diminuiu o conteúdo de todos os macronutrientes da parte aérea, raiz e planta inteira, exceto o enxofre, na raiz (Tabela 4). Notou-se que a omissão do nitrogênio, ao diminuir a absorção dos nutrientes pela planta (Tabela 4), diminuiu o crescimento da pimenta (Tabela 1) e induziu o surgimento dos sintomas visuais, como o amarelecimento uniforme das folhas mais velhas da planta. Segundo Malavolta et al. (1997) este sintoma está associado com a menor produção de clorofila. Esse fato ocorreu, pois o índice relativo de clorofila do tratamento completo foi de 26,9 e no tratamento com omissão de $\mathrm{N}$, foi de 4,6 (Tabela 1).

\section{Fósforo}

As plantas de pimenta que não receberam fósforo na solução nutritiva apresentaram diminuição na altura da planta, no diâmetro do colmo, na área foliar, no número de folhas e no índice relativo de clorofila (Tabela 1), resultando em menor produção de matéria seca da parte aérea, raiz e na planta inteira, em relação ao tratamento com solução nutritiva completa (Tabela 2). Veloso \& Muraoka (1993) também verificaram menor crescimento da pimenta-do-reino com omissão do P, comparado ao tratamento completo. As plantas suprimidas de fósforo tiveram prejuízo na produção de matéria seca pela importância deste elemento na nutrição da planta, pois ele está ligado à função estrutural, no processo de transferência e armazenamento de energia (Malavolta, 1989), influenciando em processos no metabolismo da planta como a síntese de proteínas e ácido nucleico (Mengel \& Kirkby, 2001).

A omissão de P na solução nutritiva diminuiu o teor deste nutriente tanto na parte aérea (81,8\%) como nas raízes (79,2\%) (Tabela 3). A solução nutritiva completa apresentou teor de P dentro da faixa considerada adequada por Trani et al. (1997) (3 a $7 \mathrm{~g} \mathrm{~kg}^{-1}$ ), enquanto, com a omissão do nutriente, apresentou teor de P abaixo desta faixa adequada. Notou-se também que o tratamento com omissão de $\mathrm{P}$ afetou os teores de outros nutrientes (Ca nas folhas e $\mathrm{K}$ nas raízes) quando comparado com a solução nutritiva completa (Tabela 3).
Tabela 4. Conteúdo de nutrientes na parte aérea, raiz e na planta inteira de pimenta, em função da omissão de macronutrientes na solução nutritiva. Jaboticabal, 2010

Table4. Nutrients contents in the shoot, roots and in the whole pepper plant, as a function of the macronutrients omission in the nutrient solution. Jaboticabal, São Paulo, Brazil, 2010

\begin{tabular}{|c|c|c|c|c|c|c|}
\hline \multirow[t]{2}{*}{ Tratamento } & $\mathrm{N}$ & $P$ & K & $\mathrm{Ca}$ & $\mathrm{Mg}$ & S \\
\hline & \multicolumn{6}{|c|}{ Parte aérea } \\
\hline Solução completa & 217,7 & 21,2 & 47,7 & 435,6 & 89,8 & 61,4 \\
\hline$-N$ & $17,5^{-}$ & $7,1^{-}$ & $5,8^{-}$ & $74,6^{-}$ & $24,2^{-}$ & 12,2 \\
\hline$-P$ & $109,4^{-}$ & $2,0^{-}$ & $23,0^{-}$ & $161,8^{-}$ & 49,3 & 23,2 \\
\hline$-K$ & 53,2 & $5,5^{-}$ & $5,7^{-}$ & $37,5^{-}$ & $21,0^{-}$ & $3,0^{-}$ \\
\hline - $\mathrm{Ca}$ & $47,7^{-}$ & 4,9 & $12,3^{-}$ & $82,3^{-}$ & 9,4 & $5,9-$ \\
\hline$-\mathrm{Mg}$ & $116,8^{-}$ & 16,9 & 39,9 & $177,2^{-}$ & 73,7 & 39,7 \\
\hline$-s$ & $121,5^{-}$ & $15,4^{-}$ & $26,0^{-}$ & $302,1^{-}$ & $17,7^{-}$ & $4,6^{-}$ \\
\hline DMS & 41,4 & 4,7 & 11,1 & 81,2 & 21,0 & 13,2 \\
\hline CV (\%) & 17,8 & 19,0 & 20,3 & 18,8 & 21,6 & 25,9 \\
\hline
\end{tabular}

$\begin{array}{lcccccc}\text { Solução completa } & 42,2 & 7,1^{-} & 15,5 & 114,1^{-} & 12,9^{-} & 2,7 \\ \text { - N } & 9,8^{-} & 3,8^{-} & 5,1^{-} & 46,9^{-} & 5,5^{-} & 1,3 \\ \text { - P } & 33,9^{-} & 1,2^{-} & 9,5^{-} & 79,4^{-} & 9,9 & 2,0 \\ \text { - K } & 10,8^{-} & - & - & 1,3^{-} & 2,1^{-} & 0,3 \\ \text { - Ca } & 7,9^{-} & 0,6^{-} & 1,2^{-} & 2,8^{-} & 0,3^{-} & 0,5 \\ \text { - Mg } & 41,4 & 4,7^{-} & 13,2 & 66,5^{-} & 10,9 & 3,3 \\ \text { - S } & 28,0^{-} & 3,9^{-} & 4,5^{-} & 66,0^{-} & 17,2^{+} & 10,7^{+} \\ \text {DMS } & 11,7 & 1,4 & 2,6 & 24,7 & 3,7 & 4,5 \\ \text { CV (\%) } & 19,7 & 19,55 & 15,7 & 19,3 & 18,3 & 64,5\end{array}$

\begin{tabular}{|c|c|c|c|c|c|c|}
\hline Solução completa & 259,9 & 28,3 & 63,2 & 549,8 & 102,7 & 64,1 \\
\hline$-N$ & 27,3 & $10,9^{-}$ & 11,0 & $121,5^{-}$ & $29,7^{-}$ & $13,5^{-}$ \\
\hline$-P$ & 143,6 & 3,2 & $32,5^{-}$ & 241,2 & 59,2 & $25,2^{-}$ \\
\hline$-\mathrm{K}$ & $64,0^{-}$ & $5,5^{-}$ & $5,7^{-}$ & 38,8 & $23,1^{-}$ & $3,4^{-}$ \\
\hline - $\mathrm{Ca}$ & $55,6^{-}$ & $5,5^{-}$ & $19,2^{-}$ & $85,1^{-}$ & $9,7^{-}$ & $6,5^{-}$ \\
\hline$-\mathrm{Mg}$ & $158,2^{-}$ & $21,7^{-}$ & 53,1 & $243,7^{-}$ & 84,6 & 43,0 \\
\hline$-s$ & 149,5 & $19,3^{-}$ & $30,5^{-}$ & $368,1^{-}$ & 34,9 & 15,3 \\
\hline DMS & 49,2 & 5,8 & 12,7 & 89,1 & 21,9 & 14,2 \\
\hline CV (\%) & 16,8 & 18,1 & 17,9 & 15,9 & 18,8 & 24,4 \\
\hline
\end{tabular}
Dunnett a $5 \%$ de probabilidade

A omissão de P, em relação ao tratamento com solução nutritiva completa, diminuiu o conteúdo desse nutriente na parte aérea da planta $(90,6 \%)$, nas raízes $(83,1 \%)$ e na planta inteira (88,7\%). Além disso, a omissão de $\mathrm{P}$ diminuiu o conteúdo de todos os outros nutrientes na parte aérea e na planta inteira da pimenta, exceto no conteúdo de N, Mg e S nas raízes (Tabela 4).

A omissão de $\mathrm{P}$ nas plantas de pimenta, ao provocar prejuízo no desenvolvimento vegetativo da cultura devido à menor absorção deste nutriente, resultou no aparecimento de sintomas visuais, como plantas raquíticas e com folhas mais velhas de coloração verde mais escura. Sintomas semelhantes 
foram observados por Veloso \& Muraoka (1993) em pimentado-reino. Estes sintomas foram folhas de coloração verdeazulada com tons purpúreos na face superior do limbo e ásperas ao tato, e ainda caules finos e um recurvamento para cima das folhas mais jovens e, posteriormente, nas mais velhas, sendo estas folhas pequenas e estreitas.

\section{Potássio}

As variáveis vegetativas de crescimento foram afetadas significativamente pela omissão de potássio (Tabela 1), o que acarretou em menor produção de matéria seca da parte aérea, da raiz e, consequentemente, da planta inteira quando comparada com o tratamento com a solução nutritiva completa (Tabela 2).

A ausência do K na solução nutritiva, comparada com o tratamento com solução nutritiva completa, diminuiu os teores deste nutriente na parte aérea $(55,1 \%)$ e na raiz (100\%), respectivamente (Tabela 3). Nota-se que comparando com o teor foliar de K adequado considerado por Trani et al. (1997) (30 a $50 \mathrm{~g} \mathrm{~kg}^{-1}$ ) tanto o tratamento com a solução nutritiva completa quanto o tratamento com a omissão de K estariam deficientes. Estas diferenças podem ser atribuídas ao genótipo, ao tipo de folhas coletada e às condições de cultivo serem distintas.

A omissão de $\mathrm{K}$ na solução nutritiva afetou os teores de outros nutrientes na folha, com redução nos teores de N, Ca e S, em comparação com o tratamento com solução nutritiva completa (Tabela 3). No tratamento com omissão de K, em relação ao tratamento completo, houve um aumento significativo nos teores de $\mathrm{N}$, e redução nos teores de $\mathrm{P}, \mathrm{K}$ e Ca da raiz da planta (Tabela 3). No tratamento com omissão de $\mathrm{K}$ não foi possível analisar os teores de $\mathrm{P}$ e $\mathrm{K}$ uma vez que não havia material vegetativo para tal finalidade; por isso o motivo da ausência desses teores e conteúdos, respectivamente (Tabela 3 e 4).

Com a omissão de $\mathrm{K}$, foi possível constatar, ainda, uma diminuição significativa no conteúdo de nutrientes na parte aérea e na planta inteira de todos os macronutrientes, entretanto, na raíz, não houve uma redução no conteúdo de S (Tabela 4).

Diante dos prejuízos da falta de K na solução nutritiva sob a depreciação do crescimento e a absorção de nutrientes, isto propiciou o surgimento de sintomas visuais como a clorose nas margens das folhas mais velhas, seguida de necrose. Veloso \& Muraoka (1993) também verificaram esses sintomas de deficiência de potássio na pimenta-do-reino, tendo início de necrose nas margens e pontas de folhas mais velhas, evoluindo para as folhas jovens, de consistência quebradiça, e provocando um escurecimento de áreas situadas entre as nervuras, com posterior necrose. Este efeito dos sintomas de deficiência de $\mathrm{K}$ nas folhas mais velhas é atribuído à alta redistribuição do nutriente nas plantas (Mengel \& Kirkby, 2001). Passos (1999) acrescenta, ainda, que o potássio é necessário para o desenvolvimento da clorofila. Assim, observou-se no trabalho a diminuição no índice relativo da clorofila foliar no tratamento com omissão de K em relação ao tratamento completo (Tabela 1).

\section{Cálcio}

As plantas que não receberam cálcio na solução nutritiva apresentaram menor altura, diâmetro do colmo, área foliar, número de folhas e índice relativo de clorofila (Tabela 1), acarretando em menor produção de matéria seca na parte aérea, nas raízes e na planta inteira (Tabela 2). Nota-se que o órgão mais afetado pela deficiência de Ca foi a raiz, diminuindo em $84,6 \%$ a matéria seca, o que poderia ser explicado pela função do cálcio na planta, fazendo parte das pectinas por meio dos pectatos de cálcio, sendo requerido para a alongação e a divisão mitótica celular, refletindo diretamente no crescimento radicular (Prado, 2008), justificando-se, assim, a importância deste nutriente no crescimento das raízes.

Notou-se que no tratamento com a omissão de Ca na solução nutritiva, houve diminuição nos teores de deste elemento nas plantas de pimenta em relação ao tratamento com solução nutritiva completa tanto na parte aérea (35,7\%) como nas raízes (81,9\%), respectivamente (Tabela 3). De acordo com os teores adequados de Ca sugeridos por Trani et al. (1997) (15-35 $\left.\mathrm{g} \mathrm{kg}^{-1}\right)$, verifica-se que as plantas de pimenta do tratamento com a solução nutritiva completa estavam com valores adequados.

A omissão de Ca na solução nutritiva reduziu os teores de N, Mg e S analisados na parte aérea, e P, K e Mg nas raízes (Tabela 3). Fato semelhante ocorreu no conteúdo dos nutrientes na planta, sendo que, na omissão do Ca na solução nutritiva, o conteúdo deste elemento diminuiu na parte aérea (81,1\%) e na raiz (97,5\%), em relação à planta cultivada em solução nutritiva com o cálcio. De forma semelhante ao verificado para os teores de nutrientes, a omissão de Ca na solução nutritiva diminuiu o conteúdo dos demais macronutrientes da parte aérea e na planta inteira, exceto o $\mathrm{S}$, na raiz (Tabela 4).

Diante dos efeitos depressivos da falta do cálcio nas variáveis biológicas da planta e na absorção de nutrientes pelas plantas de pimenta, verificou-se o aparecimento de desordens nutricionais visíveis na planta, como o surgimento de folhas com formas irregulares, pontos com manchas necróticas entre as nervuras das folhas e morte das brotações a partir das pontas das extremidades de folhas e raízes. Estes sintomas de deficiência de Ca são semelhantes aos descritos por Veloso \& Muraoka (1993) com pimenta, em que observaram inicialmente um leve amarelecimento das folhas mais jovens, com pequenas manchas pardas necróticas na face superior das folhas mais velhas, evoluindo para manchas necróticas nas bordas das folhas e com coloração amarelapálida na parte basal das folhas, com pequenas manchas necróticas semelhantes a pequenas pontuações.

\section{Magnésio}

Nas plantas de pimenta cultivadas com a omissão de Mg na solução nutritiva foi observada redução na altura, na área foliar, no número de folhas e no índice relativo de clorofila (Tabela 1) em relação ao tratamento com solução nutritiva completa. Notou-se também que houve uma diminuição na produção de matéria seca na parte aérea $(28,1 \%)$, na raiz $(23,1 \%)$ e na planta inteira $(27,4 \%)$, respectivamente (Tabela 2 ). 
Entretanto, a omissão deste nutriente na solução nutritiva na cultura da pimenta não influenciou o teor de Mg na parte aérea e raízes, mas diminuiu os teores de N e Ca na parte aérea como nas raízes (Tabela 3).

Os teores de Mg na parte aérea no tratamento com solução nutritiva completa tiveram valores pouco acima da faixa considerada adequada por Trani et al. (1997) (3 a $12 \mathrm{~g} \mathrm{~kg}^{-1}$ ), constatando-se que as plantas do tratamento com solução nutritiva completa estariam com concentrações suficientes do macronutriente.

O tratamento com omissão de Mg não afetou o conteúdo deste nutriente na parte aérea, raízes e planta inteira, porém, houve redução no conteúdo de $\mathrm{N}$, Ca e $\mathrm{S}$ na parte aérea, $\mathrm{P}$ e Ca nas raízes, e N, P, Ca e S na planta inteira de pimenta, em comparação ao tratamento com solução nutritiva completa (Tabela 4). O fato de a omissão do Mg não ter afetado o seu teor e conteúdo na planta, provavelmente, poderia ser explicado pela reserva existente deste nutriente no momento do transplantio das mudas de pimenta para a solução nutritiva e pela exigência da planta ser relativamente baixa.

O efeito da omissão de Mg na solução nutritiva ao provocar prejuízos no desenvolvimento vegetativo, visto anteriormente, foi suficiente para induzir os sintomas de desordem nutricional nas plantas de pimenta apresentando clorose, iniciando-se entre as nervuras das folhas mais velhas. Estes sintomas foram semelhantes aos encontrados por Veloso \& Muraoka (1993), os quais verificaram nas folhas mais velhas um amarelecimento e clorose internerval, com uma faixa estreita de tecido verde permanecendo ao longo das nervuras, evoluindo para necrose nas margens das folhas mais velhas. Vale lembrar que estes sintomas foram diagnosticados já no final do período de avaliação, uma vez que, no inicio do desenvolvimento, a reserva deste nutriente contida nas plantas impediram o aparecimento dos sintomas visuais.

\section{Enxofre}

A omissão de S na solução nutritiva provocou redução na altura, na área foliar, no número de folhas e no índice relativo de clorofila (Tabela 1), entretanto, diminuiu a produção de matéria seca da parte aérea e raízes e, consequentemente, da planta inteira (Tabela 2), quando comparado com o tratamento com solução nutritiva completa.

Salienta-se que as plantas submetidas à omissão de $\mathrm{S}$ na solução nutritiva apresentaram uma redução no teor deste nutriente na parte aérea (89,8\%), comparando-se com o tratamento com solução nutritiva completa (Tabela 3), entretanto, para o teor de $\mathrm{S}$ nas raízes, houve um incremento deste nutriente $\left(12,3 \mathrm{~g} \mathrm{~kg}^{-1}\right)$ comparado ao tratamento com solução nutritiva completa (2,0 $\mathrm{g} \mathrm{kg}^{-1}$ ) (Tabela 3). Esse resultado do teor de $\mathrm{S}$ na raiz nas plantas com a omissão do nutriente, provavelmente ocorreu pelo efeito da concentração do elemento devido à baixa quantidade de matéria seca de raiz. Salienta-se que não foram encontradas informações na literatura sobre o teor foliar adequado de S para pimenta.

Notou-se que a omissão de $\mathrm{S}$ na solução nutritiva diminuiu os teores de $\mathrm{N}, \mathrm{K}$, e Mg na parte aérea da planta, e os teores de K e Mg nas raízes das plantas de pimenta (Tabela 3). Além disso, a omissão de enxofre diminuiu o conteúdo de $\mathrm{S}$ na parte aérea (92,5\%) e na planta inteira (76,1\%), em comparação com a planta cultivada em solução nutritiva completa (Tabela 4).

Em função da diminuição da matéria seca da planta e da absorção de nutrientes, devido à ausência de $S$ na solução nutritiva, observou-se desordem nutricional nas plantas de pimenta, apenas na última semana de avaliação, surgindo folhas pequenas, com enrolamento nas margens das folhas, clorose, inicialmente nas folhas mais novas. Estes resultados foram semelhantes aos obtidos por Veloso \& Muraoka (1993) que descreveram sintomas nas folhas novas com tamanho pequeno, com coloração verde mais clara.

Observou-se no tratamento com solução nutritiva completa a seguinte ordem decrescente quanto ao conteúdo na parte aérea: $\mathrm{Ca}>\mathrm{N}>\mathrm{Mg}>\mathrm{S}>\mathrm{K}>\mathrm{P}$; nas raízes: $\mathrm{Ca}>\mathrm{N}>\mathrm{K}>\mathrm{Mg}>\mathrm{P}>\mathrm{S}$, e na planta inteira: $\mathrm{Ca}>\mathrm{N}>\mathrm{Mg}>\mathrm{S}>\mathrm{K}>\mathrm{P}$ (Tabela 4).

Veloso \& Muraoka (1993) relataram a seguinte ordem decrescente para o conteúdo de macronutrientes nas folhas: $\mathrm{K}>\mathrm{N}>\mathrm{Ca}>\mathrm{Mg}>\mathrm{S}>\mathrm{P}$. Nota-se divergência nos resultados, pois no presente trabalho foi o Ca o nutriente mais requerido pela planta, enquanto para Veloso \& Muraoka (1993) foi o K. Essas diferenças possivelmente devem-se ao genótipo e ao sistema de cultivo distinto, além do tecido vegetal coletado, pois neste experimento foi toda parte aérea e no de Veloso \& Muraoka (1993) foi apenas a folha.

\section{CONCLUSÕES}

As omissões dos macronutrientes interferiram nas concentrações dos nutrientes nas diversas partes da planta, limitando o crescimento vegetativo, refletindo na produção de matéria seca das plantas de pimenta e promovendo os sintomas característicos de deficiência de cada nutriente.

Os nutrientes que mais limitaram o desenvolvimento da pimenta foram o nitrogênio, cálcio e potássio, entretanto, o cálcio foi o mais exigido pela planta.

\section{LITERATURA CITADA}

Bataglia, O.C.; Furlani, A.M.C.; Teixeira, J.P.F.; Furlani, P.R.; Gallo, J.R. Métodos de análise química de plantas. Campinas: Instituto Agronômico, 1983. 48p. (Boletim Técnico, 78).

Chaves, S.W.P. Efeito da alta frequência de irrigação e do “mulching” plástico na produção da pimenta 'Tabasco' fertirrigada por gotejamento. Piracicaba: Escola Superior de Agricultura “Luiz de Queiroz”, 2008. 153p. Tese Doutorado.

Epstein, E. Nutrição mineral de plantas - princípios e perspectivas. Rio de Janeiro: Livros Técnicos e Científicos, 1975. 341p.

Filgueira, F.A.R. Novo manual de olericultura: agrotecnologia moderna na produção e comercialização de hortaliças. 2.ed. Viçosa: Universidade Federal de Viçosa, 2003. 412p.

Hoagland, D.R.; Arnon, D.I. The water-culture method for growing plants without soil. Berkeley: University of California/College of Agricultura/California Agricultural Experimental Station, 1950. 32p. (California Agricultural 
Experimental Station, Circular 347).

Instituto Brasileiro de Geografia e Estatística - IBGE. Censo Agropecuário: Brasil, grandes regiões e unidades da Federação, Rio de Janeiro, 2006. 777p.

Malavolta, E. ABC da adubação. São Paulo: Agronômica Ceres, 1989. 292p.

Malavolta, E.; Vitti, G.C.; Oliveira, S.A. Avaliação do estado nutricional das plantas: princípios e aplicações. 2.ed. Piracicaba: Potafós, 1997. 319p.

Mengel, K.; Kirkby, E.A. Principles of plant nutrition. 5.ed. Dordrecht: Kluwer Academic Publishers, 2001. 849p.

Passos, L.P. Fisiologia do capim-elefante: uma revisão analítica. In: Passos, L.P.; Carvalho, L.A.; Martins, C.E. (Eds.). Biologia e manejo do capim-elefante. Juiz de Fora: Embrapa Gado de Leite, 1999. p.29-62.

Prado, R.M. Nutrição de plantas. São Paulo: Editora UNESP, 2008. 417p.
Rodrigues, L.R.F. Técnicas de cultivo hidropônico e de controle ambiental no manejo de pragas, doenças e nutrição vegetal em ambiente protegido. Jaboticabal: FUNEP, 2002. 765p.

Rufino, J.L.S.; Penteado, D.C.S. Importância econômica, perspectiva e potencialidades do mercado para pimenta. Informe Agropecuário, v.27, n.235, p.7-15, 2006.

Trani, P.E.; Raij, B. Hortaliças. In: Raij, B.; Cantarella, H.; Quaggio, J.A.; Furlani, A.M.C. (Eds). Recomendações de adubação e calagem para o Estado de São Paulo. $2^{\mathrm{a}}$ ed. Campinas: Instituto Agronômico/Fundação IAC, cap.18, 1997. p.157-185. (Boletim Técnico, 100)

Veloso, C.A.C.; Muraoka, T. Diagnóstico de sintomas de deficiência de macronutrientes em pimenteira do reino (Piper nigrum, L.). Scientia Agricola, v.50, n.2, p.232-236, 1993. <http://www.scielo.br/pdf/sa/v50n2/10.pdf>. doi:10.1590/S0103-90161993000200010. 17 Mar. 2011. 